\title{
MOLECULAR AND IMMUNOHISTOCHEMICAL CHARACTERISTICS OF COMPLETE HYDATIDIFORM MOLES
}

\author{
Kubelka-Sabit $\mathrm{KB}^{1, *}$, Prodanova I ${ }^{2}$, Jasar $\mathrm{D}^{1}$, Bozinovski ${ }^{3}$, Filipovski ${ }^{1}$, Drakulevski $\mathrm{S}^{1}$,
} Plaseska-Karanfilska $\mathrm{D}^{3}$

*Corresponding Author: Dr. Katerina B. Kubelka-Sabit, Clinical Hospital Acibadem Sistina, Skupi 5a, 1000 Skopje, Republic of Macedonia. Tel: +389-70-365-338. Fax:+389-23-099-599. E-mail: catkubelka@ yahoo.co.uk; katerina.kubelka@acibademsistina.mk

\begin{abstract}
Molar pregnancy is a gestational trophoblastic disease that belongs to the category of precancerous lesions. On the other end of the spectrum are gestational trophoblastic neoplasms such as invasive mole, choriocarcinoma, placental site trophoblastic tumor and epithelioid trophoblastic tumor, which are considered malignant tumors. Based on defined histopathological criteria, molar pregnancy is divided into partial and complete hydatidiform mole. Especially in the case of early complete mole, the diagnosis can be quite challenging and often necessitates additional molecular or immunohistochemical methods. The aim of this study was to assess the importance of additional molecular and immunohistochemical methods to accurately diagnose complete hydatidiform mole and to stress the importance of correct diagnosis and close followup of these patients. A total of 367 consecutive cases of spontaneous abortion were analyzed in a 3-year period. Eight cases with histopathological diagnosis of complete molar pregnancy were selected for further analysis. Apart from standard microscopic analysis, additional molecular and immunohistochemical analyses were performed in all eight cases. Most of the histopathological characteristics of complete molar pregnancy were present in all cases, together with complete absence of positivity for the p57 immunohistochemical marker in the cytotrophoblasts and villous stromal cells. The molecular analysis revealed androgenetic diploidy in seven cases and biparental diploidy
\end{abstract}

\footnotetext{
${ }^{1}$ Department of Histopathology and Cytology, Clinical Hospital "Acibadem-Sistina”, Skopje, Republic of Macedonia

2 Diagnostic Laboratory "Histolab", Skopje, Republic of Macedonia

${ }^{3}$ Macedonian Academy of Sciences and Arts, Research Centre for Genetic Engineering and Biotechnology "Georgi D. Efremov", Skopje, Republic of Macedonia
}

in one case with more than three consecutive complete molar pregnancies. Additional immunohistochemical and molecular methods can considerably aid in the correct diagnosis of molar pregnancy.

Keywords: Biparental diploidy; Complete mole; Molecular diagnostics; p57.

\section{INTRODUCTION}

Molar pregnancy is a gestational trophoblastic disease that belongs to the category of precancerous lesions. On the other end of the spectrum are gestational trophoblastic neoplasms such as invasive mole, choriocarcinoma, placental site trophoblastic tumor and epithelioid trophoblastic tumor, which are considered malignant tumors. Each of these conditions can perforate the uterine wall, metastasize and lead to death if left untreated. Approximately $50.0 \%$ of them arise from molar pregnancy and derive from placental villous, and extra-villous trophoblast [1]. Molar pregnancy has the highest incidence of all trophoblastic diseases, estimated at 0.57 to 2/1000 pregnancies [2-5]. Higher incidences occur in Southeast Asia and Japan and lower in Australia, New Zealand, as well as Europe and North America (0.6-1.1 per 1000 pregnancies) [6,7]. Based on defined histopathological criteria, molar pregnancy is divided into partial and complete hydatidiform mole. The risk of persistent trophoblastic disease is higher in complete hydatidiform mole, compared with partial mole. For comparison, choriocarcinoma rarely occurs after partial mole, but occurs in $2.0-5.0 \%$ of cases of complete hydatidiform mole $[2,8]$. Therefore, the exact diagnosis of the products of conception is extremely important.

Histomorphological diagnostic criteria for molar pregnancy are clearly defined in the literature. Vesicular stromal edema and trophoblastic surface proliferation are the most prominent features. However, in early spontane- 
ous abortions, the differences between classical pathological changes in hydropic abortion and various types of molar pregnancy are subtle. Especially in the case of early complete mole, the diagnosis can be quite challenging. In those cases, additional molecular methods can be of use to differentiate between partial molar pregnancy, complete molar pregnancy and hydropic abortion. On the other hand, immunohistochemical analyses using certain antibodies such as p57 can differentiate between hydropic abortion and partial molar pregnancy on one side and complete molar pregnancy on the other. Moreover, when molecular methods and additional immunohistochemical analyses were used, considerable variations in the diagnosis of hydropic abortion and molar pregnancy was observed $[2-4,9,10]$. The aim of this study was to assess the importance of additional molecular and immunohistochemical methods to accurately diagnose complete hydatidiform mole and to stress the importance of correct diagnosis and close follow-up of these patients.

\section{MATERIALS AND METHODS}

A total of 367 consecutive cases of spontaneous abortion were analyzed in a 3-year period. Apart from standard microscopic analysis, additional molecular and immunohistochemical analyses were performed in all cases suspicious for complete molar pregnancy. A diagnosis of complete molar pregnancy was suspected in eight cases, based on the following histomorphological criteria: 1) presence of a heterogeneous population of chorionic villi, ranging from small to extremely large villi with pronounced edema and frequent finding of central cavitations; 2) mucous stromal degeneration; 3) karyorrhectic debris in

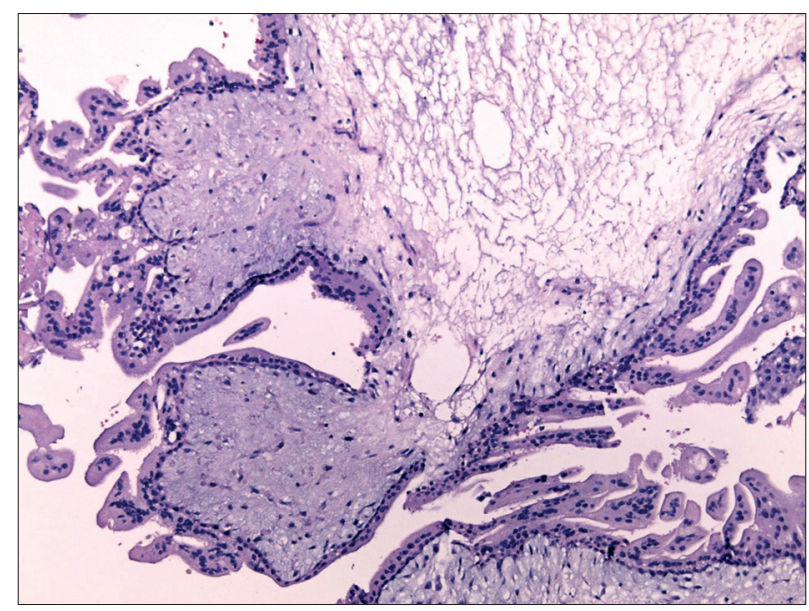

Figure 1. Microscopic appearance of the chorionic villi in complete hydatidiform mole with a pronounced stromal edema and trophoblastic proliferation (hematoxylin and eosin, $\times 100$ ). the stroma, and 4) proliferation of the sinciciotrophoblasts and cytotro-phoblasts [6] (Figures 1 and 2).

For three of the cases, fragments of placental and decidual tissue were separated prior to fixation in formalin, during the macroscopic analysis of the products of conception. This process was done by an experienced pathologist. One set of placental and decidual tissue, containing at least $\sim 30 \mathrm{~mm}^{3}$ of tissue in each container, was frozen in liquid nitrogen. A separate set of placental and decidual tissue fragments were fixed in formalin, routinely processed and embedded in paraffin, for routine histopathological and immunohistochemical analysis. For the remaining five cases, a small $\sim 30 \mathrm{~mm}^{3}$ fragment of formalin-fixed and paraffin-embedded placental and decidual tissue was taken from the processed paraffin blocks. The decidual tissue was used for extraction of maternal DNA (deoxyribonucleic acid), in cases where a maternal blood sample could not be obtained.

For the immunohistochemical analysis, primary mouse monoclonal antibodies p57 (clone 25B2) from Vector Laboratories (Burlingame, CA, USA) and Ki-67 and p63 (clone 4A4) from Ventana (Tucson, AZ, USA) were used. For the p57 antibody detection, EnVision FLEX+ kit from Dako from Agilend Technologies (Santa Clara, CA, USA) was used. The reaction was performed on an automated platform for immunohistochemistry Autostainer Link 48 from Dako from Agilent Technologies. For the p63 and Ki-67 antibody detection, ultraView Universal DAB Detection Kit from Ventana was used on an automated platform Ventana BenchMark GX. The type of the antibodies, clones and dilutions are given in Table 1.

For all antibodies used, a reaction was considered as positive if a brown signal was observed in the cell nuclei.

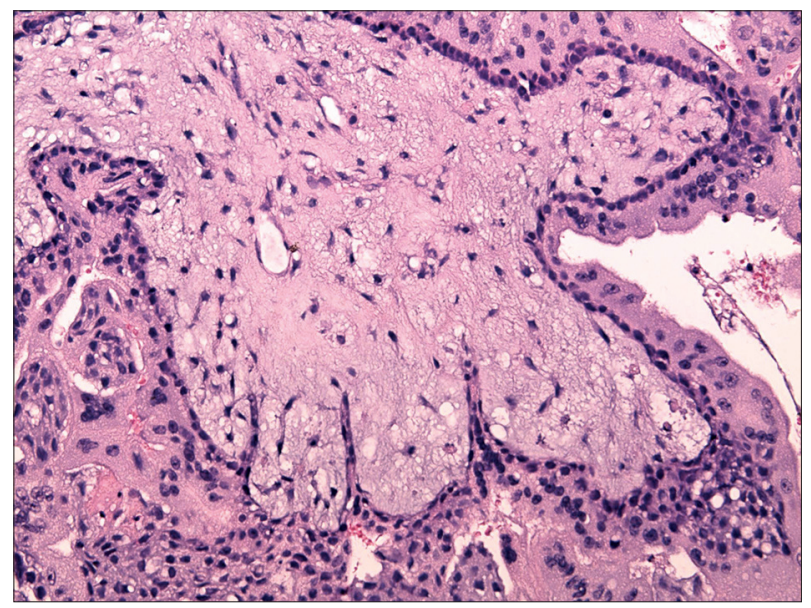

Figure 2. Mucoid stromal degeneration and irregular villous contours in complete hydatidiform mole (hematoxylin and eosin, $\times 200$ ). 
BALKAN JOURNAL OF MEDICAL GENETICS

Kubelka-Sabit KB, Prodanova I, Jasar D, Bozinovski G, Filipovski V, Drakulevski S, Plaseska-Karanfilska D

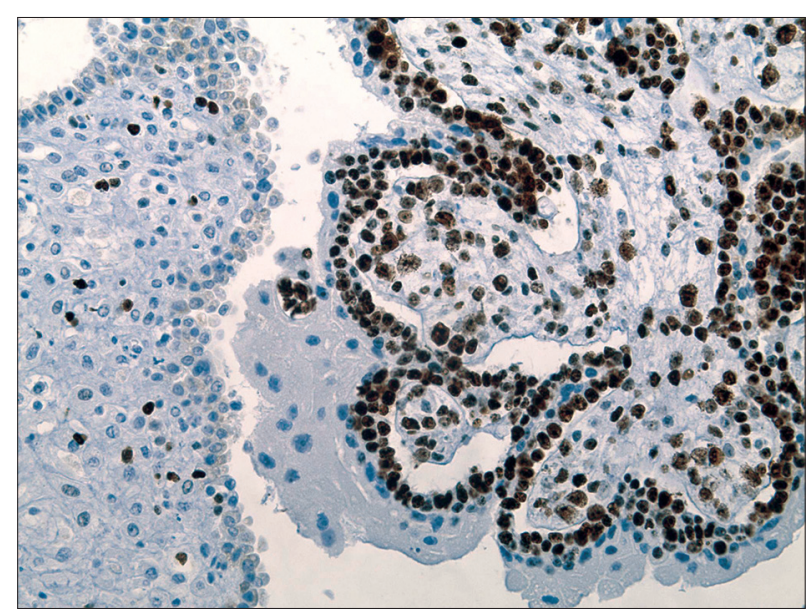

Figure 3. Ki-67 proliferation index $>50.0 \%$ in villous cytotrophoblasts $(\times 200)$.

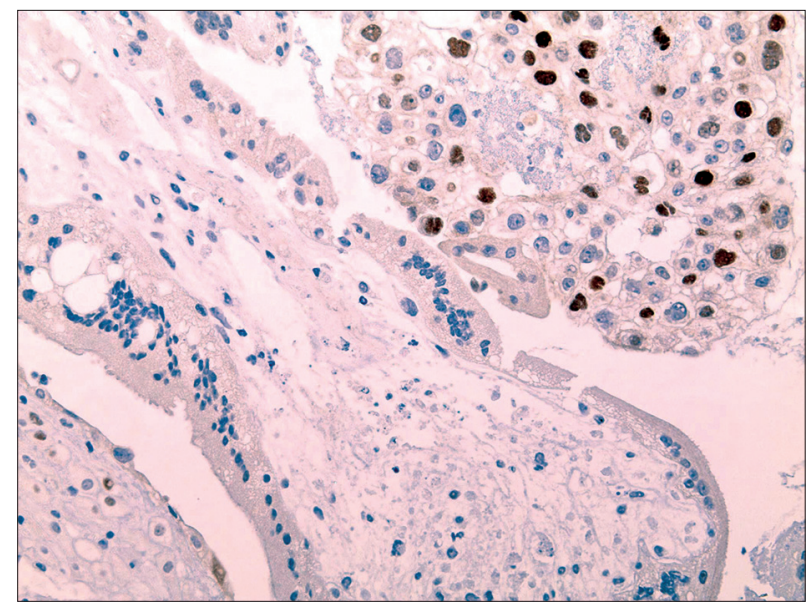

Figure 4. Absence of p57 staining In the villous cytotrophoblasts and villous stromal cells $(\times 200)$.

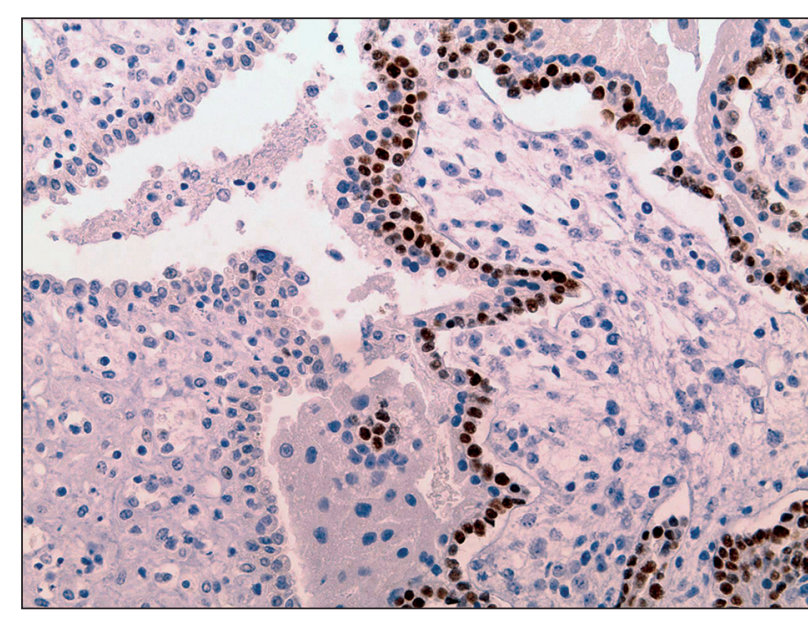

Figure 5. p63 staining in $>50.0 \%$ of the villous cytotrophoblasts $(\times 200)$.

The positivity for the antibodies was evaluated in the cytotrophoblastic cells as percentage of positive cells. The staining intensity for p57 and p63 antibodies was evaluated
Table 1. Primary antibodies with clones and dilutions.

\begin{tabular}{|l|c|c|}
\hline Primary Antibody (producer) & Clone & Dilution \\
\hline $\begin{array}{l}\text { Monoclonal mouse anti-human } \\
\text { Ki-67 antigen (Ventana) }\end{array}$ & MIB-1 & RTU \\
\hline $\begin{array}{l}\text { Monoclonal mouse primary } \\
\text { antibody anti-p63 (Ventana) }\end{array}$ & $4 \mathrm{~A} 4$ & RTU \\
\hline $\begin{array}{l}\text { Monoclonal mouse Primary } \\
\text { antibody anti-p57 (Vector Laboratories) }\end{array}$ & Kip2 & $1: 50$ \\
\hline
\end{tabular}

RTU: ready to use.

as: 0 (no staining); $[+]$ (weak staining); $[++]$ (moderate staining); $[+++]$ (intense staining).

In order to evaluate the ploidy and to distinguish maternal from paternal allelles, a molecular analysis of placental and decidual tissue (or maternal blood cells) was performed. The quantitative fluorescent polymerase chain reaction (QF-PCR) molecular method was performed on ABI-PRISM ${ }^{\text {TM }} 3100$ and 3500 Genetic Analyzers (Applied Biosystems, Foster City, CA, USA). In a multiplex PCR reaction, four DNA markers on chromosomes 18 (D18 S535, D18S391, D18S390 and D18S386), 21 (D21S1435, D21S1446, D21S1411 and D21S1414), 13 (D13S631, D13 S305, D13S258 and D13S1817), two markers on the $\mathrm{X}$ chromosome (DXS6803 and HPRT), and amelogenin locus (AMXS) were analyzed.

\section{RESULTS}

Histopathological Analyses. In all eight complete moles, chorionic villi with irregular jagged villous contours, heterogenous population of chorionic villi, stromal edema, mucous stromal degeneration and trophoblastic nuclear atypia were found. Circumferential trophoblastic proliferation was found in $7 / 8(87.5 \%)$ cases, whereas cytotrophoblastic proliferation was present in 5/8 (62.5\%) cases. Karyorrhectic stromal debris was present in $2 / 8$ $(25.0 \%)$ of the cases (Table 2$)$.

On the other hand, when compared to the defined histopathological criteria for partial hydatidiform mole there was only a slight overlap (Table 3 ). In fact, two types of villi or presence of fetal erythrocytes were not found in any of the cases, whereas focal trophoblastic proliferation and trophoblastic stromal inclusions were present in one of the cases. On the other hand, irregular villous contours were seen in all eight cases.

Immunohistochemistry. In all eight complete mole cases, the Ki-67 proliferation index was higher than 50.0\% (Table 4, Figure 3). There was a complete absence of positivity for the p57 immunohistochemical marker in the cytotrophoblasts and villous stromal cells in all cases, ir- 
Table 2. Histopathological characteristics of complete mole.

\begin{tabular}{|l|c|c|}
\hline $\begin{array}{l}\text { Complete Mole } \\
\text { Characteristics }\end{array}$ & $\begin{array}{c}\text { Absent or } \\
\text { Present }\end{array}$ & $\begin{array}{c}\text { Complete } \\
\text { Mole Cases } \\
\boldsymbol{n = 8 ( \% )}\end{array}$ \\
\hline $\begin{array}{l}\text { Heterogenous population } \\
\text { of villi }\end{array}$ & $\begin{array}{c}\text { absent } \\
\text { present }\end{array}$ & $\begin{array}{c}0(0.0) \\
8(100.0)\end{array}$ \\
\hline $\begin{array}{l}\text { Circumferential trophoblastic } \\
\text { proliferation }\end{array}$ & $\begin{array}{c}\text { absent } \\
\text { present }\end{array}$ & $\begin{array}{c}1(12.5) \\
7(87.5)\end{array}$ \\
\hline $\begin{array}{l}\text { Cytotrophoblastic } \\
\text { proliferation }\end{array}$ & absent & $3(37.5)$ \\
\hline present & $5(62.5)$ \\
\hline Kuclear atypia & absent & $0(0.0)$ \\
debris & present & $8(100.0)$ \\
\hline & absent & $6(75.0)$ \\
present & $2(25.0)$ \\
\hline
\end{tabular}

Table 3. Histopathological characteristics of partial mole.

\begin{tabular}{|l|c|c|}
\hline $\begin{array}{l}\text { Partial Mole } \\
\text { Characteristics }\end{array}$ & $\begin{array}{c}\text { Absent or } \\
\text { Present }\end{array}$ & $\begin{array}{c}\text { Complete } \\
\text { Mole Cases } \\
\boldsymbol{n}=\mathbf{8}(\%)\end{array}$ \\
\hline Two types of villi & $\begin{array}{c}\text { absent } \\
\text { present }\end{array}$ & $\begin{array}{c}8(100.0) \\
0(0.0)\end{array}$ \\
\hline Irregular villus contours & absent & $0(0.0)$ \\
present & $8(100.0)$ \\
\hline Trophoblastic stromal & absent & $7(87.5)$ \\
inclusions & present & $1(12.5)$ \\
\hline Focal trophoblastic & absent & $7(87.5)$ \\
proliferation & present & $1(12.5)$ \\
\hline Presence of fetal & absent & $8(100.0)$ \\
erythrocytes & present & $0(0.0)$ \\
\hline
\end{tabular}

respective of the genetic origin of the chromosomes (Table 4, Figure 4). For the p63 marker, the percentage of stained cytotrophoblasts was between 60.0 and $80.0 \%$ in all eight cases (Table 4, Figure 5). In one case, the staining intensity was weak, in three it was moderate, whereas a strong staining signal was observed in four cases.

Molecular Analyses. The QF-PCR analysis was performed in all eight cases. Androgenetic diploidy was found in seven of them (87.5\%), whereas in one case, the genetic analysis showed biparental diploidy. According to the clinical data obtained for this patient, she had previously suffered seven early miscarriages. The last three products of conception were submitted for analysis in our laboratory. They all showed histopathological evidence of early complete molar pregnancy and were biparental diploidies with a 46,XX genotype. In fact, the initial curettage submitted for analysis was due to persistent complete mole, for which the patient was treated with methotrexate. After 1 year, the next pregnancy also showed histopathological evidence of complete molar pregnancy, with chromosomal characteristics of biparetal diploidy. One year later, after
Table 4. Immunohistochemical characteristics of complete moles.

\begin{tabular}{|c|c|c|c|}
\hline $\begin{array}{c}\text { Positive } \\
\text { Cells (\%) }\end{array}$ & $\begin{array}{c}\text { Ki-67 } \\
\text { Antibody } \\
\boldsymbol{n}=\mathbf{8}\end{array}$ & $\begin{array}{c}\mathbf{p 6 3} \\
\text { Antibody } \\
\boldsymbol{n}=\mathbf{8}\end{array}$ & $\begin{array}{c}\mathbf{p 5 7} \\
\text { Antibody } \\
\boldsymbol{n}=\mathbf{8}\end{array}$ \\
\hline$n(\%)$ & $n(\%)$ & $n(\%)$ \\
\hline 0 & $0(0.0)$ & $0(0.0)$ & $8(100)$ \\
\hline 10 & $0(0.0)$ & $0(0.0)$ & $0(0.0)$ \\
\hline 20 & $0(0.0)$ & $0(0.0)$ & $0(0.0)$ \\
\hline 30 & $0(0.0)$ & $0(0.0)$ & $0(0.0)$ \\
\hline 40 & $0(0.0)$ & $0(0.0)$ & $0(0.0)$ \\
\hline 50 & $0(0.0)$ & $0(0.0)$ & $0(0.0)$ \\
\hline 60 & $0(0.0)$ & $3(37.5)$ & $0(0.0)$ \\
\hline 70 & $4(50.0)$ & $2(25.0)$ & $0(0.0)$ \\
\hline 80 & $3(37.5)$ & $3(37.5)$ & $0(0.0)$ \\
\hline 90 & $1(12.5)$ & $0(0.0)$ & $0(0.0)$ \\
\hline 100 & $0(0.0)$ & $0(0.0)$ & $0(0.0)$ \\
\hline
\end{tabular}

the third miscarriage with complete molar phenotype and biparental diploidy genotype, this patient was considered as a possible case of familial recurrent hydatidiform mole. Due to the supposed clinical syndrome and repeated molar pregnancies, the patient was consulted against future spontaneous pregnancies and was offered in vitro fertilization with oocyte donation. She was also referred for further genetic investigation about her condition.

The second patient was diagnosed in the 15 th week of gestation with a twin pregnancy. Apart from the normal fetus, the patient had a complete molar pregnancy. She was treated with methotrexate due to elevated $\beta$ human chorionic gonadotropin (bHCG) serum levels. Seventeen months later, a resection of the left uterine horn was performed due to suspected ruptured left cornual pregnancy. The material submitted for histopatohhological analysis consisted of soft, hemorrhagic and partially necrotic tumorous tissue. Subsequent microscopic analysis revealed that the tumor had morphological characteristics of placental site trophoblastic tumor. It had infiltrated the myometrium and had given numerous vascular emboli.

In order to accurately assess the risk category of the placental site trophoblastic tumor, we had to prove whether it originated from the previous complete molar pregnancy. Therefore, QF-PCR analysis was performed on the placental tissue sample from the complete molar pregnancy and from the tumor tissue. The genetic profiles of both placental and tumor tissue were identical, thus proving that the tumor originated from the placental mole. Therefore, the patient was classified in the low risk category. After excluding metastatic disease, the patient underwent total hysterectomy with bilateral adnexectomy. She is alive 
and without disease after 14 months of follow-up. The follow-up period of the other six patients was uneventful.

\section{DISCUSSION}

The complete hydatidiform mole is mainly diploid and usually has two sets of paternal chromosomes. In $80.0-90.0 \%$ of cases, it results from fertilization of an empty egg with a sperm that is then reduplicated in the homozygous diploid genome. In this case, the karyotype is always $46, \mathrm{XX}$, as $46, \mathrm{YY}$ is non viable. Less often, complete mole is a consequence of dispermic fertilization (diandric diploidy) of an empty egg, so the karyotype can be $46, X Y$ or $46, X X$.

However, there are rare cases of tetraploid or biparental diploid complete moles [5,8,11-14]. This must be kept in mind when evaluating products of conception, as the diagnosis of complete mole should not be excluded based on molecular analysis alone.

It is of great importance not to miss a diagnosis of complete mole, because persistent trophoblastic disease can occur in $15.0-25.0 \%$ of these cases [12]. The data in our study correlate with this incidence. In fact, two of the eight patients $(25.0 \%)$ had persistent trophoblastic disease. One of these patients is still unable to have a successful pregnancy due to recurrent complete moles, whereas the other patient had to have her uterus removed for malignant trophoblastic tumor. The latter patient had twin pregnancy with normal fetus and complete hydatidiform mole. This is a very rare event, occurring in 1 in 20,000 to 1 in 100,000 pregnancies, and can be associated with fetomaternal complications such as persistent gestational trophoblastic disease [15]. The case with twin molar and non molar pregnancy was the only one in our series that was complicated with occurrence of placental site trophoblastic tumor, consistent with the above mentioned results. Other investigators suggest that the risk of persistent trophoblastic disease is the same as for patients with singleton complete molar pregnancy [16].

Although the histopathological criteria for diagnosis of partial and complete molar pregnancy are clearly defined in the literature, unfortunately they are not always present in histological slides, especially in case of early molar pregnancy. For example, in the study of Paul et al. [17], 21 cases of molar pregnancy were reevaluated using flow cytometry and immunohistochemical analysis of p57 marker. It was found that only six of the 21 cases were really molar pregnancies [17].

According to Golfier et al. [4], there is a significant difference in the accuracy of diagnosis of molar preg- nancy if the analysis was performed by an experienced pathologist. Apart from the accumulated experience that allows more accurate determination of the histological criteria, this study found that the experienced pathologists significantly more often $(41.0 \%)$ use additional immunohistochemical markers such as p57 to confirm the histological diagnosis. In fact, these investigators believe that adequate and relevant clinical differentiation between partial, complete molar pregnancy and hydropic abortion can be achieved if the slides are evaluated by an experienced pathologist in this field, but only if additional immunohistochemical or molecular techniques are used [4].

All eight cases in this study were evaluated by an experienced pathologist, with the use of additional immunohistochemical and molecular analyses. In this way, it was possible to confirm the diagnosis of complete mole using immunohistochemistry even in the case of biparental diploidy.

Additional immunohistochemical analyses are often used in the literature to distinguish between partial and complete molar pregnancy $[2,4,9,10,18]$. This method is simple and quick and can be performed without the need for expensive equipment [2].

The most useful antibody to confirm a diagnosis of complete mole is $\mathrm{p} 57[8,10]$. The $\mathrm{p} 57 \mathrm{Kip} 2$ protein is a cyclin-dependent kinase inhibitor. It is the protein product of the CDKN1C gene, located on chromosome $11 \mathrm{p} 15.5$ and is paternally imprinted and maternally expressed. Thus, since the complete molar pregnancy is missing genetic material from the mother, it is not expected to show $C D K N 1 C$ gene expression $[3,8-10,19]$. On the other hand, the cases of hydropic abortions (biparental diploidy) and partial molar pregnancy (diandric triploidy) are expected to show p57 positivity in the cytotrophoblasts and villous stromal cells. However, cases of biparental diploid complete moles also have abnormal, androgenetic pattern of p57Kip2 expression rather than that seen in other types of biparental conceptuses. This is probably due to abnormal imprinting, being a common mechanism underlying the development of biparental diploid complete mole [20].

The immunohistochemical analysis for the p57 marker confirmed all seven cases of androgenetic diploidy as complete molar pregnancies, whereas in the one case of biparental diploidy, the absence of the p57 marker in the cytotrophoblasts and villous stroma was the only back up for the histopathological diagnosis of early complete mole. Other investigators have also been able to differentiate cases of hydropic abortion and partial mole from complete mole cases, based on immunohistochemistry for $\mathrm{p} 57$. They have not found $\mathrm{p} 57$ positivity in the cytotrophoblasts or 
villous stroma in any of the complete mole cases tested, unlike partial mole or hydropic abortion $[8,10]$.

The transcription factor p63 is a homologue of the p53 gene and is localized in the long arm of the third chromosome (3q27-29). Its expression in normal placenta is located in the cytotrophoblasts and the protein is considered to have an important role in the maintenance of stem cells, as well as growth and development of various epithelial tissues. Its role in the diagnosis of gestational trophoblastic disease is not yet fully clarified $[2,21]$. There are conflicting reports regarding the utility of p63 in molar pregnancies. For example, in the study of Erfanian et al. [2], the p63 marker has not shown any positivity in synciciotrophoblasts or cytotrophoblasts in the cases of a non molar pregnancy, while positivity has been found in all cases of partial or complete mole. According to these investigators, p63 may be an ideal marker of differentiation between hydropic abortion and molar pregnancy, but not between partial and complete mole [2]. On the other hand, in the study by Ramalho et al. [21] that included 39 cases of hydropic abortion, molar pregnancy and choriocarcinoma, no statistically significant difference was found in the number of p63-positive cytotrophoblasts between hydropic abortion cases and partial or complete hydatidiform mole. However, they did notice a difference in staining intensity between cases of partial and complete mole [21].

In our opinion, this marker should be tested on a larger series of cases in order to reliably determine its value in the diagnostic algorithm for molar pregnancies. Our one case of recurrent complete hydatidiform mole posed a serious diagnostic difficulty when the molecular results from the second pregnancy were compared to the histopathological results. The morphological changes of the placenta, suggestive of complete mole, were very subtle and pronounced trophoblastic proliferation can sometimes be observed in early normal pregnancies. However, after the patient's third spontaneous abortion, we insisted on detailed clinical data and found that the patient had previously suffered had at least three early spontaneous abortions, some of them regarded as complete moles based on histopathological findings alone (at different institutions). The histopathological, immunohistochemical and molecular findings from all three products of conception of this patient were re-evalulated and our conclusion was that this was a possible case of familial recurrent hydatidiform mole. These women have an inherited predisposition to diploid biparental molar pregnancies [22]. Most of the cases are due to maternal homozygous and compound heterozygous recessive gene mutations in the NLRP7 gene [23], and less commonly in the $K H D C 3 L$ gene $[7,24]$. The NLRP7 gene belongs to the NLRP (nucleotide-binding, leucine-rich repeat, pyrin domain) family and is located at 19q13.4. The NLRP7 protein is thought to be involved in imprinting multiple maternal genes in oocytes that contribute to a developing embryo, ensuring that the genes will be inactive; the corresponding paternal genes are active. This protein is also involved in cell proliferation and differentiation [25]. Its role in inflammation and apoptosis has also been reported [24]. The NLRP7 gene was the first identified recessive gene involved in recurrent hydatidiform mole and mutations have been reported in $48.0-80.0 \%$ of patients with more than 50 mutations identified to date [7]. The best chance for our patient to have a normal pregnancy is probably through oocyte donation. Successful pregnancies after recurrent complete moles with oocyte donation have been reported in the literature [26]. It has also been suggested that intracytoplasmic sperm injection, followed by selection of male embryos, can prevent recurrence of complete moles in these patients [27]. Moreover, all three recurrent complete moles in our patient had female genotypes $(46, \mathrm{XX})$. Nonetheless, Fisher et al. [28] published a case of three recurrent biparental moles with two female and one male genotype. Therefore, selection of male embryos is unlikely to prevent complete mole recurrence in these patients [28].

There have been reports of an increased recurrence risk of $0.85-1.0 \%$ for women who have experienced an initial complete molar pregnancy in comparison to the normal population $[29,30]$. However, according to Eagles et al. [29], one in 640 women with complete mole has the rare condition of familial recurrent hydatidiform mole. They had evaluated clinical data from 16,000 women and concluded that recurrent hydatidiform mole accounts for most, but not all, cases of women with three or more complete moles. They have not found significant difference in need for chemotherapy between typical sporadic complete mole and diploid biparental complete mole [29]. Unfortunately, other investigators have also found that neither morphological nor immunohistochemical features can reliably predict subsequent requirements for chemotherapy in complete hydatidiform moles [31].

In our study, there were two cases with persistent hydatidiform mole and need for chemotherapy. One was the case of presumptive familial recurrent hydatidiform mole. The other case of androgenetic diploid complete mole subsequently developed a placental site trophoblastic tumor. Based on our results, although on a limited number of cases, the risk of persistent trophoblastic disease is the same, irrespective of the genetic origin of the complete mole.

Different genetic analyses can be used as a complementary method with the classical histopathological 
analysis. The methods of in situ hybridization and flow cytometry can be used to assess the cell ploidy, in order to distinguish the diploid complete mole or hydropic abortion from the triploid partial mole. However, these analyses cannot distinguish between diploid complete molar pregnancy and diploid hydropic abortion, triploid non molar and partial molar pregnancy, or between mono and dispermic complete mole or androgenetic or biparental complete mole. Molecular genotyping, such as QF-PCR, is a superior compared to the former methods, because it can recognize paternal and maternal alleles [8].

In conclusion, evaluation of the products of conception suspicious for molar pregnancy should be individualized in each laboratory, depending on technical requirements and experience of the staff. If more sophisticated molecular techniques are not available, the pathologist should at least determine the cell ploidy and/or use a p57 immunohistochemical marker. Additional immunohistochemical and molecular methods can considerably aid in the correct diagnosis of a molar pregnancy.

Declaration of Interest. The authors report no conflicts of interest. The authors alone are responsible for the content and writing of this article.

\section{REFERENCES}

1. Hui P, Baergen R, Cheung ANY, Fukunaga M, Gersell $\mathrm{D}$, Lage JM, et al. Gestational trophoblastic disease. In: Kurman RJ, Carcangiu ML, Herrington CS, Young RH, Eds. WHO Classification of Tumours of Female Reproductive Organs, 4th ed. Lyon, France: IARC Press. 2014: 155-168.

2. Erfanian M, Sharifi N, Omidi AA. P63 and Ki-67 expression in trophoblastic disease and spontaneous abortion. J Res Med Sci. 2009; 14(6): 375-384.

3. Fernández J, Cortes R, Salazar A, Pulido A, Dabed B, Garcia V. p57 kip2 immunohistochemistry: Ancillary technique in hydatidiform moles diagnosis. BMC Proceedings. 2013; 7(2): P33.

4. Golfier F, Clerc J, Hajri T, Massardier J, Frappart L, Duvillard $\mathrm{P}$, et al. Contribution of referent pathologists to the quality of trophoblastic diseases diagnosis. Hum Reprod. 2011; 26(10): 2651-2657.

5. Sundvall L, Lund H, Niemann I, Jensen UB, Bolund L, Sunde L. Tetraploidy in hydatidiform moles. Hum Reprod. 2013; 28(7): 2010-2020.

6. Heidarpour M, Khanahmadi M. Diagnostic value of P63 in differentiating normal gestation from molar pregnancy. J Res Med Sci. 2013; 18(6): 462-466.
7. Carey L, Nash BM, Wright DC. Molecular genetic studies of complete hydatidiform moles. Transl Pediatr. 2015; 4(2): 181-188.

8. Kipp BR, Ketterling RP, Oberg TN, Cousin MA, Plagge AM, Wiktor AE, et al. Comparison of fluorescence in situ hybridization, p57 immunostaining, flow cytometry, and digital image analysis for diagnosing molar and nonmolar products of conception. Am J Clin Pathol. 2010; 133(2): 196-204.

9. Landolsi H, Missaoui N, Yacoubi MT, Trabelsi A, Rammeh-Rommani S, Hidar S, et al. Assessment of the role of histopathology and DNA image analysis in the diagnosis of molar and non-molar abortion: a study of 89 cases in the center of Tunisia. Pathol Res Pract. 2009; 205(11): 789-796.

10. Sarmadi S, Izadi-Mood N, Abbasi A, Sanii S. p57KIP2 immunohistochemical expression: A useful diagnostic tool in discrimination between complete hydatidiform mole and its mimics. Arch Gynecol Obstet. 2011; 283(4): 743-748.

11. Niemann I, Petersen LK, Hansen ES, Sunde L. Differences in current clinical features of diploid and triploid hydatidiform mole. BJOG. 2007; 114(10): 1273-1277.

12. Fukunaga M. Immunohistochemical characterization of p57Kip2 expression in tetraploid hydropic placentas. Arch Pathol Lab Med. 2004; 28(8): 897-900.

13. Bewtra C, Frankforter S, Marcus JN. Clinicopathologic differences between diploid and tetraploid complete hydatidiform moles. Int J Gynecol Pathol. 1997; 16(3): 239-244.

14. Candelier JJ. [Complete hydatidiform mole]. Med Sci (Paris). 2015; 31(10): 861-868.

15. Chen, CP, Ko TM, Chen CY, Wang TY, Chern SR, Kuo YL, et al. First-trimester molecular diagnosis of complete hydatidiform mole associated with dizygotic twin pregnancy conceived by intrauterine insemination. Taiwan J Obstet Gynecol. 2014; 53(4): 572-578.

16. Niemann I, Sunde L, Petersen LK. Evaluation of the risk of persistent trophoblastic disease after twin pregnancy with diploid hydatidiform mole and coexisting normal fetus. Am J Obstet Gynecol. 2007; 197(1): 45.e1-e5.

17. Paul M, Goodman S, Felix J, Lewis R, Hawkins M, Drey E. Early molar pregnancy: Experience in a large abortion service. Contraception. 2010; 81(2): 150-156.

18. Banet N, DeScipio C, Murphy K, Beierl K, Adams E, Vang R, et al. Characteristics of hydatidiform moles: 
Analysis of a prospective series with p57 immunohistochemical and molecular genotyping. Mod Pathol. 2014; 27(2): 238-254.

19. Sasaki S, Sasaki Y, Kunimura T, Sekozawa A, Kojima Y, Iino K. Clinical Usefulness of immunohistochemical staining of p57 kip2 for the differential diagnosis of complete mole. Biomed Res Int. 2015; 2015: 905648.

20. Fisher RA, Hodges MD, Rees HC, Sebire NJ, Seckl MJ, Newlands ES, et al. The maternally transcribed gene p57(KIP2) (CDNK1C) is abnormally expressed in both androgenetic and biparental complete hydatidiform moles. Hum Mol Genet. 2002; 11(26): 3267-3272.

21. Ramalho LN, Maggiori MS, Ribeiro-Silva A, Peres LC. P63 expression in hydropic abortion and gestational trophoblastic diseases. Placenta. 2006; 27(6-7): 740-743.

22. Hemida R, van Doorn H, Fisher R. A novel genetic mutation in a patient with recurrent biparental complete hydatidiform mole: A brief report. Int J Gynecol Cancer. 2016; 26(7): 1351-1353.

23. Parry DA, Logan CV, Hayward BE, Shires M, Landolsi $\mathrm{H}$, Diggle $\mathrm{C}$, et al. Mutations causing familial biparental hydatidiform mole implicate c6orf221 as a possible regulator of genomic imprinting in the human oocyte. Am J Hum Genet. 2011; 89(3): 451-458.

24. Murdoch S, Djuric U, Mazhar B, Seoud M, Khan $\mathrm{R}$, Kuick R, et al. Mutations in NALP7 cause recurrent hydatidiform moles and reproductive wastage in humans. Nat Genet. 2006; 38(3): 300-302.
25. Hayward BE, De Vos M, Talati N, Abdollahi MR, Taylor GR, Meyer E, et al. Genetic and epigenetic analysis of recurrent hydatidiform mole. Hum Mutat. 2009; 30(5): E629-E639.

26. Akoury E, Gupta N, Bagga R, Brown S, Dery C, Kabra M, et al. Live births in women with recurrent hyda-tidiform mole and two NLRP7 mutations. Reprod Biomed Online. 2015; 31(1): 120-124.

27. ReubinoffBE, Lewin A, Verner M, Safran A, Schenker $\mathrm{JG}$, Abeliovich D. Intracytoplasmic sperm injection combined with preimplantation genetic diagnosis for the prevention of recurrent gestational trophoblastic disease. Hum Reprod. 1997; 12(4): 805-808.

28. Fisher RA, Khatoon R, Paradinas FJ, Roperts AP, Newlands ES. Repetitive complete hydatidiform mole can be biparental in origin and either male or female. Hum Reprod. 2000; 15(3): 594-598.

29. Eagles N, Sebire NJ, Short D, Savage PM, Seckl MJ, Fisher RA. Risk of recurrent molar pregnancies following complete and partial hydatidiform moles. Hum Reprod. 2015; 30(9): 2055-2063.

30. Sebire NJ, Fisher RA, Foskett M, Rees H, Seckl MJ, Newlands ES. Risk of recurrent hydatidiform mole and subsequent pregnancy outcome following complete or partial hydatidiform molar pregnancy. BJOG. 2003; 110(1): 22-26.

31. Petts G, Fisher RA, Short D, Linday I, Seckl ML, Sebire NJ. Histopathological and immunohistochemical features of early hydatidiform mole in relation to subsequent development of persistent gestational trophoblastic disease. J Reprod Med. 2014; 59(5-6): 213-220. 